\title{
TRATAMENTO CIRÚRGICO NA RECIDIVA RETROPERITONEAL TARDIA POR CARCINOMA RENAL DE CÉLULAS CLARAS APÓS NEFRECTOMIA RADICAL
}

\author{
SURGICAL TREATMENT FOR LATE RENAL CELL CARCINOMA RECURRENCE IN THE \\ RENAL FOSSA AFTER RADICAL NEPHRECTOMY
}

\author{
Carlos Márcio Nóbrega de Jesus, ACBC- SP1; Filemón Anastásio Silva Casafus²; \\ Aparecido Donizetti Agostinho ${ }^{3}$
}

\section{INTRODUÇÃO}

O comportamento do carcinoma renal de células claras (CRCC) após a nefrectomia radical por vezes se apresenta imprevisível. Embora a maioria das recidivas neoplásicas ocorra dentro dos primeiros dois anos de seguimento e sejam mais comuns em pulmões e ossos, alguns relatos citam recidivas tardia após vários anos de acompanhamento e em várias localizações ${ }^{1}$. A recorrência local após nefrectomia radical é um eventualidade rara, que ocorre em aproximadamente $2 \%$ dos casos ${ }^{2}$.

Em virtude de se tratar de uma situação rara sem um tratamento padrão a ser seguido e devido CRCC apresentar maus resultados a quimioterapia e radioterapia, há o interesse no manuseio deste seleto grupo de pacientes. Neste contexto, relatamos um caso de recorrência retroperitoneal tardia do CRCC após nefrectomia radical, tratado por exérese cirúrgica com resultado satisfatório em curto prazo.

\section{RELATO DO CASO}

Homem de 57 anos, assintomático, em acompanhamento ambulatorial em nossa instituição há dois anos em virtude de nefrectomia radical à esquerda realizada em outro serviço, por adenocarcinoma de células claras, Grau 3. Há quatro anos e meio de acompanhamento, foi observado na tomografia abdominal massa retroperitoneal de $7 \mathrm{~cm}$ em topografia renal esquerda com captação de material de contraste (Figura 1). Nos exames realizados previamente em seu acompanhamento não havia evidência de recidiva tumoral até este momento.

Afastada a possibilidade de metástases em outros órgãos, foi programada exploração cirúrgica, com anuência do paciente dos riscos e da eventualidade de recidiva após o ato cirúrgico. Foi realizada incisão subcostal ampliada e observou-se uma massa de aproximadamente $9 \mathrm{~cm}$ aderida à aorta porém com plano de clivagem. A mesma foi retirada com mínima perda sanguínea $(300 \mathrm{ml})$ (Figura 2) sem outras

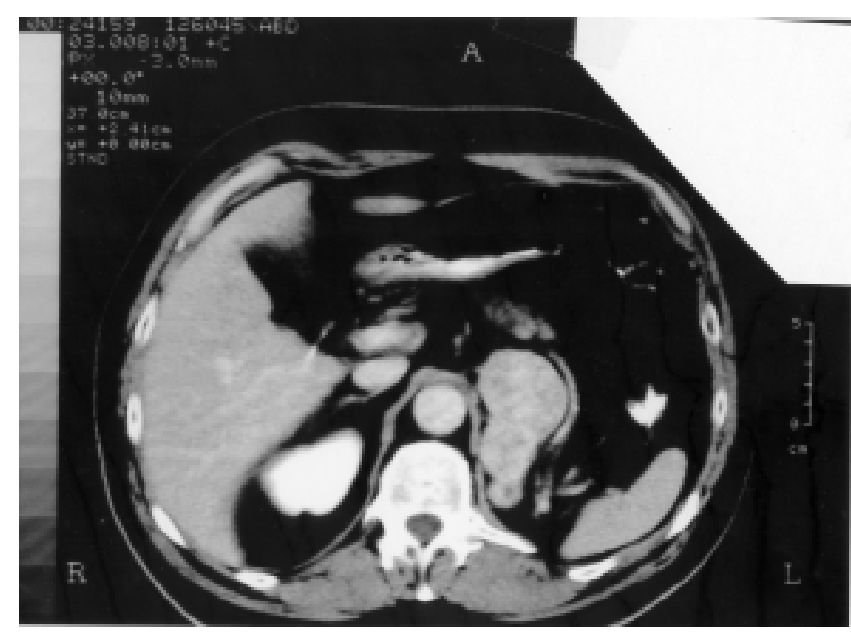

Figura 1 - Tomografia computadorizada de abdomen demonstrando recidiva neoplásica com realce após infusão de contraste em topografia renal. $O$ diagnóstico foi realizado após quatro anos e meio da realização de nefrectomia radical esquerda.

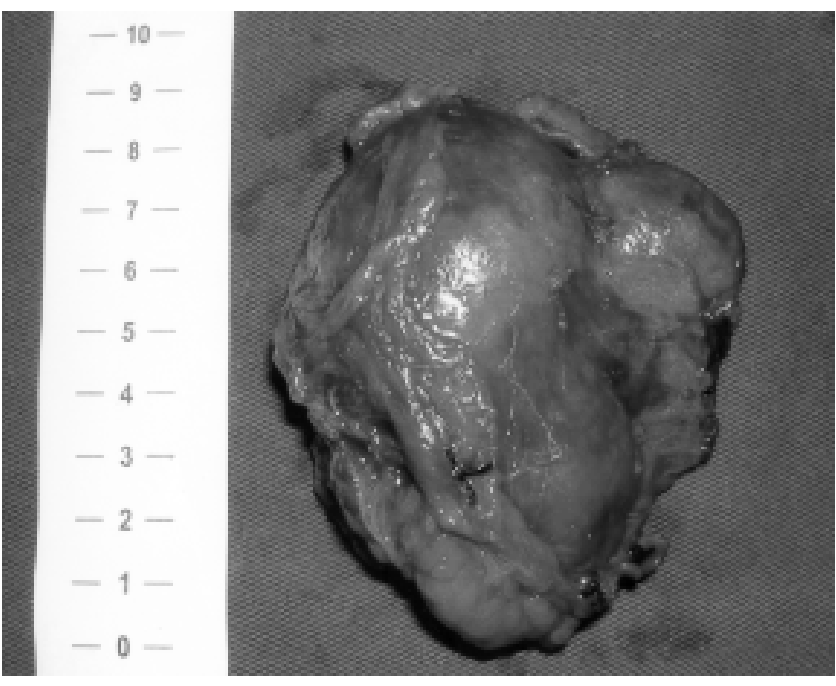

Figura 2 - Macroscopia da peça operatória.

\footnotetext{
1. Doutor em Urologia da Faculdade de Medicina de Botucatu - Universidade Estadual Paulista (UNESP).

2. Médico Residente do Departamento de Urologia - Faculdade de Medicina de Botucatu - Universidade Estadual Paulista( UNESP).

3. Doutor em Urologia da Faculdade de Medicina de Botucatu Departamento de Urologia - Faculdade de Medicina de Botucatu - Universidade Estadual Paulista (UNESP).
}

Recebido em 22/11/2005

Aceito para publicação em 28/01/2006

Conflito de interesses: nenhum

Fonte de financiamento: nenhuma

Trabalho realizado no Hospital das Clínicas de Botucatu - Universidade Estadual Paulista (UNESP), Botucatu, São Paulo - SP. 
intercorrências. O paciente apresentou boa evolução com alta hospitalar no $4^{\circ}$ dia de pós-operatório. $\mathrm{O}$ estudo anatomopatológico confirmou o diagnóstico de recidiva de CRCC Grau 3. Uma tomografia abdominal realizada após seis meses do ato operatório não se evidenciou recidiva tumoral no leito cirúrgico. Não houve tratamento adicional para este paciente.

\section{DISCUSSÃO}

A recorrência local de CRCC após nefrectomia radical é um evento raro. Em um estudo retrospectivo 30 pacientes apresentaram recorrência local de CRCC, correspondendo a $1,8 \%$ das nefrectomias realizadas naquele Serviço. Embora a taxa de sobrevida observada fosse ruim ( $28 \%$ em cinco anos), os pacientes que se submeteram ao procedimento de exérese da massa obtiveram uma melhora na sobrevida de $51 \%$ comparados a $13 \%$ daqueles que somente foram observados ${ }^{2}$.

Em virtude de o CRCC ser uma neoplasia pouco responsiva a tratamentos adjuvantes, o tratamento cirúrgico deve ser a primeira opção em recidiva retroperitoneal única após a nefrectomia radical, especialmente após os dois anos de seguimento.

No presente relato, utilizamos a via transperitoneal aberta por apresentar melhor abordagem da massa no intraoperatório, principalmente devido a sua proximidade com a aorta. No entanto, a via laparoscópica mão assistida foi utilizada com sucesso para retirada de recidiva tumoral após nefrectomia radical com o propósito de oferecer ao paciente um procedimento pouco invasivo ${ }^{3}$. Apesar de realizarmos esta técnica cirúrgica em nosso serviço, acreditamos que a via convencional facilitou a exposição e liberação da massa.

Finalmente, acreditamos que a tomografia computadorizada abdominal não deve ser negligenciada e ser realizada anualmente, mesmo após o segundo ano de acompanhamento, para o diagnóstico de recidiva tardia. Nos casos em que esta ocorra de forma isolada, o tratamento cirúrgico deve ser oferecido na tentativa de estender a sobrevida deste seleto grupo de pacientes.

\begin{abstract}
Late renal cell carcinoma recurrence in the renal fossa is a rare event. This condition occurs in 1 to $2 \%$ of radical nephrectomies. We reported a late recurrence at the renal fossa about four and half years after radical nephrectomy due to a renal cell carcinoma (RCC) without metastasis elsewhere. Diagnosis in an outpatient follow-up was made during an abdominal computed tomography and we observed a retroperitoneal mass in the renal fossa. The excision at the recurrence area was made through a subcostal transversal incision without any difficulty. After 6 months from this second procedure, there was no evidence of recurrence. The surgical aggressive treatment for late retroperitoneal RCC recurrence is a good method in this rare situation. Abdominal computed tomography must be done during long periods of follow-up for patients with radical nephrectomy for RCC to search for late retroperitoneal recurrences (Rev. Col. Bras. Cir. 2007; 34(6): 437-438).
\end{abstract}

Key words: Carcinoma, renal cell; Recurrence; Nephrectomy; Surgery.

\section{REFERÊNCIAS}

1. Dekernion JB, Ramming KP, Smith RB. The natural history of metastatic renal cell carcinoma: a computer analysis. J Urol. 1978;120(2):148-52.

2. Itano NB, Blute ML, Spotts B, Zincke H. Outcome of isolated renal cell carcinoma fossa recurrence after nephrectomy. J Urol. 2000;164(2):322-5.

3. Nakada SY, Johnson DB, Hahnfield L, Jarrard DF. Resection of isolated fossa recurrence of renal-cell carcinoma after nephrectomy using hand- assisted laparoscopy. J Endourol. 2002;16(9):687-8.
Como citar este artigo:

Jesus CMN, Casafus FAS, Agostinho AD. Tratamento cirúrgico na recidiva retroperitoneal tardia por carcinoma renal de células claras após nefrectomia radical. Rev Col Bras Cir. [periódico na Internet] 2007; 34(6). Disponível em URL: http://www.scielo.br/rcbc

Endereço para correspondência:

Dr. Carlos Márcio Nóbrega de Jesus

Departamento de Urologia - Faculdade de Medicina de Botucatu, unesp

Rubião Júnior S/N

CEP: 18618- 000

Fone/Fax: 14- 3811-6271

E-mail: marcio@fmb.unesp.br 